\title{
PARA VS. QUE EM ORAÇÕES ENCAIXADAS NO PB*
}

Danniel Carvalho

Universidade Federal de Alagoas

Resumo: Este trabalho discute alguns problemas gerados pela assunção tradicional de para como complementizador encabeçando estruturas infinitivas encaixadas no $\mathrm{PB}$, através do processo de reanálise. São tecidas algumas considerações a partir de evidências empíricas que desfavorecem tal proposta. É sugerida uma revisão da análise de Salles (2000) sobre para encabeçando uma oração infinitiva equivalente a que em orações subjuntivas. É feita também uma descrição dos dois tipos de estrutura a fim de verificar a força do traço lexical de para.

Palavras-chave: Preposição; complementizador; infinitivo; subjuntivo; duplicação

\section{Introdução}

Alguns fenômenos lingüísticos no Português Brasileiro (PB) intrigam muitos estudiosos e põem em xeque algumas posições teóricas. Uma dessas questões envolve o infinitivo no PB que, junto a pouquíssimas outras línguas (Português Europeu (PE), Holandês, Galego, Húngaro, por exemplo), pode apresentar flexão morfológica de concordância. $O$ estatuto da presença/ausência de flexão morfologicamente visível no infinitivo para o PB não é algo pacífico (isso não quer dizer que para as outras línguas o seja, porém não pretendo contemplá-las neste trabalho) e envolve algumas questões de cunho sintático-semântico dentro da sentença. Há ainda outras características do infinitivo no $\mathrm{PB}$, como sua natureza, a possível

\footnotetext{
Uma primeira versão deste trabalho foi apresentada inicialmente na mesaredonda "Variação e mudança lingüística na sintaxe do português brasileiro", no II Congresso Acadêmico da Universidade Federal de Alagoas, em outubro de 2005. Agradeço a Claudia Roberta Tavares Silva e Dorothy Bezerra Silva de Brito pela leitura atenciosa da primeira versão deste texto e das conseqüentes sugestões. Qualquer erro remanescente é de minha responsabilidade. Danniel Carvalho é doutorando em Lingüística pela Universidade Federal de Alagoas.
} 
presença de sujeito realizado (DP lexical) na estrutura encaixada e a possibilidade de um pronome oblíquo nessa posição "sujeito" no caso de infinitivo preposicionado. Essas questões formam o pano de fundo para a discussão que me proponho fazer.

Há alguns estudos, dentro da perspectiva da Gramática Gerativa chomskyana, mais especificamente na Teoria de Princípios e Parâmetros (CHOMSKY, 1981, 1986, 1993) e em sua versão minimalista (CHOMSKY, 1995), sobre estruturas encaixadas infinitivas encabeçadas por preposição no PB (cf. ROCHA, 1989 sobre a preposição de; BOTELHO PEREIRA \& RONCARATTI, 1993 e SALLES, 2000 sobre a preposição para). Neste artigo, farei algumas observações sobre as estruturas infinitivas encabeçadas por para, discutindo as propostas das referências acima. O objetivo principal será verificar a natureza categorial de para e a conseqüência disso para a sentença em construções encaixadas infinitivas e subjuntivas em que aparece, assumindo ser ele um elemento com traço lexical forte, no caso de encabeçar o infinitivo, ou fraco, precedendo o subjuntivo, diferentemente da proposta de Salles (2000), segundo a qual para encabeçando o infinitivo é um complementizador, equivalente a que+subjuntivo, no $\mathrm{PB}$. Na seção 2 , realizo uma revisão das propostas de análise sobre a natureza do infinitivo e da preposição em sentenças encaixadas, inclusive a hipótese de reanálise, utilizada por Salles (op.cit.). Em seguida, na seção 3, faço algumas considerações sobre a proposta de para como um complementizador similar ao que em orações subjuntivas, sugerindo uma reanálise alternativa para a preposição para, seguindo os mesmos princípios de Salles (op.cit.), mas chegando a conclusões diferentes.

\section{Para como complementizador}

Antes de iniciarmos a discussão a respeito do tratamento da preposição para como complementizador, equiparando-o a que, no $\mathrm{PB}$, é necessário tecer algumas considerações sobre a natureza do infinitivo e da preposição nas construções encaixadas.

O infinitivo flexionado pode ser explicado, segundo Raposo (1987), através da combinação dos parâmetros INFL(ection "flexão") e de Sujeito Nulo. Na maioria das línguas, INFL é [+finito] quando especificado pelo traço [+AGR], possibilitando a presença de um sujeito lexical, que recebe Caso (nominativo) de INFL. Já INFL [- 
finito] é especificado por PRO ou traço-NP, que não exigem atribuição de Caso, uma vez que não são realizados foneticamente ${ }^{1}$. $O$ sujeito lexical do infinitivo flexionado (um fusão desses dois parâmetros, para Raposo) é autorizado, portanto, ou da elevação de INFL infinitivo ([-T]) para $C$ (infinitivos de natureza categorial $C P$ sem sujeito lexical) ou da percolação da INFL matriz à INFL encaixada (infinitivos de natureza IP). Essa questão é trazida para essa discussão apenas no intuito de verificar uma proposta explicativa para a presença de flexão no infinitivo, que não aparece nas demais línguas e, portanto, é tido como um elemento $[+\mathrm{N}]$.

Para o PE, ainda segundo Raposo (op.cit.), a posição sujeito é legitimada apenas com a presença da flexão no infinitivo. Nos casos de infinitivo não-flexionado, este aparece apenas sob controle. Isso quer dizer que a presença de um DP lexical na estrutura encaixada prescinde da presença de flexão no infinitivo:

(1) a) A Maria ligou antes de [nós chegarmos].

b) A Maria ligou antes de [PRO chegar].

c) *A Maria ligou antes de [ nós chegar- $\emptyset$ ].

Como se verifica em (1), o infinitivo pode ser encabeçado por preposição (o que nos interessa diretamente neste trabalho), mais frequientemente com de, $a$ e para, no Português (tanto PB quanto PE, exceto com para, no PE).

Segundo Rocha (1989), essas preposições têm um comportamento semelhante ao de complementizadores tradicionais: a preposição $a$ ocorre somente em estruturas de controle obrigatório não permitindo o preenchimento da posição sujeito, comportando-se como um operador do tipo $\mathrm{Wh}$; já as preposições de e para seriam introdutoras de orações cujos sujeitos podem apresentar referentes iguais ou diferentes dos da oração matriz, o que comprova, segundo a autora, a impossibilidade de regência do sujeito encaixado pela preposição encabeçadora. Para chegar a essa conclusão, a autora concebe de como um "real" complementizador de infinitivo e para

Não é pertinente para a discussão a possibilidade de se atribuir Caso nulo a PRO, como sugerem Chomsky \& Lasnik (1995). 
como uma "preposição-complementizador" nos casos de ECM em contextos de encaixamento.

A partir dessa proposta, Botelho-Pereira \& Roncaratti (1993), para explicar o fenômeno da alternância entre EU e MIM como sujeito de orações encaixadas infinitivas introduzidas por para no PB, sugerem dois tipos de para para duas estruturas distintas. São propostas pelas autoras as seguintes estruturas em (3) para as construções em (2) através do processo de reanálise da preposição proposto por Lightfoot (1991):

(2a) Maria disse pra eu sair.

(2b) Maria disse pra mim sair.

(3a) ...disse $\left[\mathrm{sP}\right.$ para $\left[\mathrm{sc} \emptyset\left[\mathrm{sF}\right.\right.$ eu $\left[\mathrm{F}^{\prime} \mathrm{F}\right.$ [sv sair $\left.\left.\left.\left.]\right]\right]\right]\right]^{2}$

(3b) ...disse[sp para[sc mim [F F [sv sair]]]]

A proposta sugere haver dupla interpretação também do infinitivo: um flexionado (autorizado pela presença de FLEX (ou AGR) em COMP) e outro não-flexionado (ausência de FLEX), diferentemente do que é proposto por Raposo para o PE. Ou seja, haveria dois tipos de infinitivo: um quando aparecesse a forma nominativa do pronome de primeira pessoa do singular (nos moldes de Raposo) (ex.: Maria disse pra eu sair- $\varnothing$ ) e outro quando a forma oblíqua do pronome aparecesse (ex.: Maria disse para mim sair).

Em Salles (2000) é proposta a existência de uma correlação entre as estruturas de (4) e (5) no que se refere às condições de licenciamento do DP encaixado, baseada na semelhança da sintaxe do sistema pronominal de ambas as línguas (PB e Inglês). A partir dessas estruturas, ela desenvolve sua análise:

(4) a) Maria comprou um livro para $\mathrm{mim} / \mathrm{ti}$ ler

b) Maria comprou um livro para $e u / t u$ ler/leres

(5) Mary bought a book for me/you to read

Mantive a notação original de Salles (2000) no exemplo (3), onde a autora usa SC (Sintagma Complementizador) pela sigla $\mathrm{cm}$ inglês CP (Complementizer Phrase), que adoto neste trabalho. 
É com base em Lightfoot (1991), Botelho Pereira \& Roncaratti (1993) e Madeira (1995), que Salles propõe uma reanálise das estruturas em (4) para uma dupla categorização de para, e aponta uma relação estreita entre a estrutura do inglês médio e a do português, afirmando que o infinitivo em (4b) é flexionado. Para tal, Salles cita a duplicação da sentença proposta por Lightfoot (op.cit.), possível em $\mathrm{PB}$, mas não em Português Europeu (PE), que deflagra, em predicados ditransitivos, o complemento preposicionado da oração matriz, "separando-o" da frase encaixada adjungida.

(6) a) Maria comprou um livro (para mim/eles) para eu/eles ler(em)

b) Maria comprou um livro (para mim/eles) para mim/eles ler

Lightfoot assume com Raposo (1987a, apud LIGHTFOOT, op.cit) que

o sujeito nominativo da oração infinitiva é licenciado mediante movimento do verbo infinitivo para uma categoria funcional/flexional abstrata (CONC) na oração encaixada, a qual, para atribuir o caso nominativo ao sujeito, deve, por sua vez, receber Caso de um verbo ou de uma preposição.

Assim, em (6b) não há morfologia flexional no infinitivo, o que permite a atribuição do Caso oblíquo ao sujeito da oração encaixada. Já em (6a), o verbo infinitivo cujo sujeito é eu seria flexionado. O traço de flexão existente em (6a) surge, portanto, do movimento de $\mathrm{T}$ para C, como já visto anteriormente (cf. RAPOSO, 1987).

Baseada nisso, Salles faz uma comparação entre estruturas em que há um regente alternativo para o sujeito encaixado (para, em ( $7 a$ ) e complementizador- $\varnothing$, em (7b)):

(7) a) Para mim/eles fazer isso vai ser difícil

b) Eu/eles fazer(em) isso vai ser difícil

É importante ressaltar que a reanálise foi proposta inicialmente para estruturas como em (8), em que, segundo a autora, tem-se o for em substituição ao caso morfológico marcador do dativo benefactivo no Inglês:

(8) It is pleasant [for the rich] [for the poor] to do the hard work "É agradável para os ricos para os pobres fazer o trabalho árduo" 
É agradável para os ricos os pobres fazerem o trabalho árduo

Também é assumido pela autora, para o PB, a proposta de Madeira (1995) para o PE em construções com predicados epistêmicos-declarativos, onde $\mathrm{C}$ é vazio de conteúdo semântico, obrigando a inversão do auxiliar no $\mathrm{PE}$ (movimento de $\mathrm{T}$ para $\mathrm{C}$ ), o que não aconteceria com os demais predicados, como com verbos factivos (cf. (9)). Salles (op.cit.) então sugere que, já que em PB não é possível essa inversão, para aparece em contrapartes de estruturas desse tipo: em verbos não epistêmico-declarativos, para é movido para $\mathrm{C}$, sendo reanalisado como complementizador e, portanto, não autorizando a inversão (cf. (10)).

(9) PE

a) Afirmou terem eles saído.

b) *Afirmou eles terem saído.

c) Fez eles saírem. ${ }^{3}$

(10) PB

a) *Afirmou terem eles saído.

b) Afirmou eles terem saído.

c) Ordenou para ele fazer isso.

d) *Ordenou para fazer ele isso.

Salles, enfim, propõe uma comparação entre as estruturas com para do $\mathrm{PB}$ e as do inglês com for (complementizador). Mas verifiquemos novamente a estrutura em (7), repetida em (11):

(11) a) It is pleasant [for the rich] [for the poor] to do the hard work

b) "É agradável para os ricos para os pobres fazer o trabalho árduo"

c) É agradável para os ricos os pobres fazerem o trabalho árduo

d) É agradável para os ricos que os pobres façam o trabalho árduo

3 Salles (2000) não dá exemplos além dos reproduzidos em (9) para predicados epistêmico-declarativos. Os exemplos restantes em (9) e (10) são acrescentados por mim. 
Na sentença do inglês, em (11a), o primeiro for é uma preposição atribuidora do Caso objetivo ao DP pronominal e o segundo for, um complementizador que introduz uma sentença infinitiva. No PB, esse tipo de estrutura pode ser representado com um complementizador nulo (11c) ou um complementizador realizado ${ }^{4}$ (11d), mas não com para na sentença encaixada. Então, comparando a estrutura do Inglês com suas correspondentes no $\mathrm{PB}$, podemos ver que o primeiro para, simetricamente ao primeiro for, é uma preposição, que autoriza a realização do DP. Entretanto, no $\mathrm{PB}$, não há um correspondente simétrico ao segundo for, sendo esta posição preenchida, no $\mathrm{PB}$, por um complementizador nulo ou o que complementizador seguido de um verbo finito(11c-d respectivamente).

Porém, é a partir dessa estrutura ${ }^{5}$ que é proposta, por Salles (op.cit.), uma equiparação da forma do infinitivo "flexionado" em (4b) com que+subjuntivo, com as sentenças em (12), que, segundo a autora, estariam em distribuição complementar.

(12) a) Maria comprou um livro para $e u / t u$ ler/leres

b) Maria comprou um livro para que $e u / t u$ leia/leias

c) *Maria comprou um livro para que mim leia

Mas, de acordo com a comparação feita acima, conclui-se que, na verdade, o for-complementizador do Inglês tem apenas o

Também é possível a presença de se encaixado como em (i):

(i) É agradável para os ricos se os pobres fizessem o trabalho árduo.

5 Observe que há um problema quanto à escolha, pela autora, do contexto estrutural: ao utilizar os exemplos de (2), é sugerida uma análise envolvendo um verbo dissendi, mas toda a análise feita por Salles (2000) se baseia em verbos ditransitivos como comprar. Inicialmente, há uma superficial correlação estrutural entre o infinitivo flexionado com para e o subjuntivo com verbos do tipo dissendi,

(i) Disse pra eu fazer.

(ii) Disse que eu fizesse.

Entretanto, essa correlação é virtual, pois a proposta alternativa de análise que proponho também contempla esse tipo de estrutura, pois essas estruturas também são suscetíveis a duplicação e a reanálise como proposta mais adiante na seção 3 . 
complementizador que como correspondente em $\mathrm{PB}$. O para, ao aparecer na estrutura finita subjuntiva, surge numa posição mais alta do que que, sendo este o responsável pela finitude da sentença, uma vez que age como barreira a qualquer transmissão de traços que para pudesse ter à sentença encaixada ${ }^{6}$, que pode ser verificada na impossibilidade da presença de uma forma oblíqua na oração encaixada, como em (12c).

A seguir, tecerei algumas considerações a respeito da proposta de para como complementizador equivalente a que com subjuntivo, baseando-me nos comentários feitos até então, e propondo uma posição alternativa para a preposição para.

\section{Algumas considerações}

Como vimos na seção anterior, é proposto, a partir da comparação de estruturas encaixadas infinitivas do PB e do Inglês, que o para encabeçando a oração infinitiva é um complementizador equivalente ao que em orações subjuntivas. Essa proposta se baseia em construções do Inglês Médio, quando se verificou a reanálise de for como um complementizador (cf. Jarad, 1997).

Revendo as sentenças em (11a-d), podemos verificar que o DP os ricos tem um comportamento distinto do DP os pobres, por serem argumentos de elementos distintos ([para] os ricos comporta-se como complemento do AP É agradável, enquanto os pobres aparece na posição sujeito da oração infinitiva). Observemos as sentenças em (13):

(13) a) [AP É agradável [PP para [DP OS ricos [CP $\oslash$ [IP OS pobres [ fazerem o trabalho árduol]]]]]

b) [AP É agradável [Pp para [DP OS ricos [CP $\varnothing L_{\mathrm{IP}}$ eu $\Gamma_{\mathrm{I}}$ fazer $\mathrm{O}$ trabalho árduo[]]]]

c) *[AP É agradável [PP para [DP Os ricos [CP $\varnothing$ [IP $_{\mathrm{IP}} \operatorname{mim}\left[_{1}\right.$ fazer o trabalho árduo] ]1]]]

6 É cliaro que essa proposta esbarra em alguns pontos cruciais sobre uma flexão não-visível do infinitivo. Mas esta questão não será contemplada nesse trabalho por motivo de espaço e delimitação do tema. 
d) [AP É agradável [PP para [DP $\operatorname{mim}$ [CP $\varnothing$ [IP eu [I fazer o trabalho árduo]]]]]]

e) [AP É agradável [PP para [DP os ricos [CP que [IP' os pobres $\left[_{\mathrm{I}}\right.$ façam o trabalho árduo]]]]]]

f) [AP É agradável [PP para [DP os ricos [CP que [IP eu [I faça o trabalho árduo]]]]]]

g) [AP É agradável [PP para [DP mim [CP que [IP' eu [IP faça o trabalho árduo]]]]]]

h) *[AP É agradável [pp para [DP mim [CP que [IP mim [I faça o trabalho árduo]]]]]]

i) *[AP É agradável [PP para [DP $\operatorname{mim}_{1}\left[\mathrm{CP}\right.$ que [IP $\mathrm{PRO}_{1}$ [ faça o trabalho árduo]]]]]

Como já foi dito na seção 2 , a sentença em (13a) corresponde àquela cuja reanálise é proposta para o inglês. Se pronominalizarmos os DPs em (13), veremos mais claramente a função de cada um na estrutura. Em (13b) vemos que eu está encaixado no CP infinitivo, onde não há nenhum elemento que licencie a forma oblíqua, causando a agramaticalidade de (13c), onde mim ocupa aquela posição. Já em (13d) onde o para possui um traço lexical forte, é licenciada a forma oblíqua. Em (13e-i), onde aparece um complementizador realizado preenchendo $\mathrm{C}$, o comportamento dos elementos na sentença muda: a presença do complementizador "forte" que exige apenas uma forma verbal finita, não aceitando na sentença encaixada uma forma pronominal oblíqua, nem um sujeito não realizado sob controle (PRO), por conta da barreira existente (CP) (cf. Pires, 2001). Portanto, em estruturas como as de (13), não é possível uma equiparação de para com um complementizador, pois é clara sua posição dentro do PP complemento na oração matriz.

Mas voltemos às estruturas propostas por Salles (2000) como sendo equivalentes à forma subjuntiva com que, em (14a):

(14) a) Maria comprou um livro [cP para [IP eu[r F [vp ler]]]] (SALLES, 2000)

b) Maria comprou um livro [* ${ }_{\mathrm{CP}}$ que [IP $\mathrm{eu}[\mathrm{r} \cdot \mathrm{F}$ [vp lesse]]]]]

c) Maria comprou um livro [ ${ }^{*} \mathrm{pP}$ para [DP $\mathrm{mim}$ [CP [C que [IP eu [r $\mathrm{F}$ [vp lesse]]]]]]] 
d) Maria comprou um livro [pp ø [pp [p para [cP [c que[ip eu[r F [vp lesse]]]]נ]]]

A correspondente (substituta) de (14a) com subjuntivo, segundo proposta de Salles, seria (14b) que, em $\mathrm{PB}$, não é boa ${ }^{7}$. E, sabendo que o verbo comprar exige um complemento oblíquo (preposicionado), este não poderia ser realizado, pois causaria também agramaticalidade (14c). Entretanto, ao assumirmos um para inserido na oração encaixada, ele não substitui que, mas o antecede estruturalmente.

Assim, sugiro que em sentenças como as com o verbo comprar em (14a), construídas com para e uma oração infinitiva encaixada, ocorre um processo de duplicação do PP complemento de comprar, proposto inicialmente por Lightfoot (1991): o primeiro para continua sendo parte da estrutura argumental de comprar, autorizando a forma oblíqua do complemento preposicionado (que pode ou não vir realizado foneticamente), e o segundo para seria reanalisado como uma preposição que pode ter: a) traço lexical forte, subcategorizando um IP, no caso de orações infinitivas encaixadas; ou b) traço lexical fraco, um CP, no caso de orações subjuntivas ${ }^{8}$. Desta forma, a presença de $\mathrm{CP}$ em construções infinitivas encaixadas desse tipo não seria necessária, não precisando, assim, haver movimento para licenciar a estrutura. Entretanto, não trato o $\mathrm{P}$ resultado da duplicação como um argumento de $\mathrm{V}$ matriz, mas como sendo um adjunto necessariamente requerido por sua relevância pragmática (cf. SCHULTE, 2001). Evidentemente esta discussão não cabe no escopo deste trabalho e será retomada em uma discussão posterior.

\section{Conclusão}

Este trabalho é parte de reflexões minhas sobre as estruturas infinitivas encaixadas preposicionadas no PB. Procurei aqui testar a validade da proposta de que para em orações encaixadas infinitivas

7 Na verdade, podemos ter uma interpretação de (14b) da seguinte forma: Maria comprou um livro que ela acha que eu consigo ler. Porém, esta leitura demanda um contexto muito específico.

8 Assumo aqui a proposta de Grimshaw (1991) e Thráinsson (1996) apud Costa e Gonçalves (1999) de que "fuctional categories are only projected when necessary" (p.68). 
com DP lexical pronominal é reanalisado como um complementizador, podendo assim ser correlacionado com o complementizador que antecedente de uma oração subjuntiva (SALLES, 2000). Os exemplos mostrados indicam que a proposta de reanálise como é feita é incompatível com construções encaixadas, pois o para não é substituído por que na conversão de infinitivas em subjuntivas, mas aparece obrigatoriamente antecedendo o complementizador, funcionando, assim, como uma preposição com traço lexical enfraquecido, caso contrário, geraria sentenças agramaticais. Quanto à natureza categorial do para da oração adjungida, vimos que, na estrutura encaixada, este não preenche $C$, mas é fruto de uma duplicação do PP complemento do verbo matriz reinterpretado ora como ainda uma preposição com traço lexical forte, subcategorizando um IP, mas não deixando de ser um adjunto, ora com o traço lexical enfraquecido, subcategorizando um $\mathrm{CP}$ subjuntivo. Algumas questões importantes, como a possibilidade de $\mathrm{mim} / \mathrm{eu}$ coocorrerem dentro do IP infinitivo e/ou a interferência da natureza de para na alternância entre estes pronomes no $\mathrm{PB}$, não foram trazidas para o texto, mas serão tratadas em trabalhos futuros.

\section{Referências}

BOTELHO-PEREIRA, M. A. \& RONCARATI, C. N. O caso do sujeito em orações infinitivas introduzidas por 'para' no português do Rio. In: Revista D.E.L.T.A., v.9, n.1, 1993.

COSTA, J. \& GONÇALVES, A. Minimal Projections: evidence from defective constructions in European Portuguese. In: Catalan Work Papers in Linguistics, v.7, 1999, p. 59-69.

CHOMSKY, N. Barriers. Cambridge, Mass.:, MIT Press, 1986.

CHOMSKY, N.; LASNIK, H. A teoria dos princípios e parâmetros. In: CHOMSKY, N. O programa minimalista. Tradução, apresentação e notas à tradução: Eduardo Paiva Raposo. Lisboa: Caminho, 1999, p. 51-195.

JARAD, N. The origin and development of for-infinitives. PhD dissertation, University of Wales, 1997.

LIGHTFOOT, D. How to set parameters: arguments from language change. Cambridge: MIT Press, 1991. 
MADEIRA, A.M. Topics in Portuguese Syntax: the licensing of T and D. PhD dissertation, University College of London, 1995.

PIRES, A.M.G. The Syntax of Gerunds and Infinitives: Subjects, Case and Control. PhD dissertation, University of Maryland, College Park, 2001.

RAPOSO, E. Case theory and Infl-to-Comp: the inflected infinitive in European Portuguese. Linguistic Inquiry, 18(1), p.85-109.

ROCHA, M. A. de F. Complementizadores no Português do Brasil: uma abordagem inter- e intra-sistêmica. In: TARALLO, F. (org.). Fotografias Sociolingüísticas. Campinas: Pontes/ UNICAMP, 1989.

SALLES, H.M.M. Preposição para introdutora de orações infinitivas. Boletim da Associação Brasileira de Lingüística (ABRALIN), Florianópolis - SC, v. 1, p. 1061-1067, 2000.

SCHULTE, K. Pragmatic Relevance as Cause for Syntactic Change: The emergency of prepositional complementizer in Romance. In: BLAKE,B. \& BURRIDGE, K. Historical Linguistics 2001: Selected Papers from the 15th International Conference on Historical Linguistics, Melbourne, 13-17 August 2001. p. 377-389. Amsterdam: J. Benjamins. 